•研究报告・

\title{
中国竹类植物馆藏标本现状与地理分布
}

\author{
许祖昌(D1,2, 罗亚皇 ${ }^{3}$, 秦声远 ${ }^{1,2}$, 朱光福 1,2 , 李德铢 (D1,2*
}

1. 中国科学院昆明植物研究所中国西南野生生物种质资源库, 昆明 650201; 2. 中国科学院大学昆明生命科学学院, 昆明 650201; 3. 中国 科学院昆明植物研究所东亚植物多样性与生物地理学重点实验室, 昆明 650201

摘要：馆藏标本是分类学研究的主要凭证，对特定类群标本的采集信息进行细致整理和分析，有助于理解该类群研究的历 史、现状和不足。此外, 结合最新的系统学研究成果和相应的环境数据构建生态位模型, 可以加深人们对特定类群分类与分 布状况的认识。被子植物的分类鉴定常基于繁殖性状进行, 然而, 竹类植物一般进行克隆繁殖, 只有在经过长期的营养生长 之后，才会进行有性生殖并同时死亡。因此，国内的竹类标本大多仅记录了营养性状，具有繁殖性状的标本数量稀少。由于 这一特殊的生物学习性, 竹类植物是当今分类学研究中最为困难的类群之一。本研究基于全国竹类植物馆藏标本的采集数据, 分析了我国竹类标本的采集和保藏现状; 利用比值法和斜率法从采集地理偏差和采集类群偏差两方面评估了竹类植物标本 的采集完整度; 结合气候数据，利用模型模拟的方法分析了影响不同竹类分支分布的主要因素。采集信息分析结果表明，国 内标本馆对竹类标本的收集和保藏存在很大的不均衡性, 且对研究团队具有较高的依赖性; 其次竹类标本的采集量的变化较 好地反映了国内植物分类学研究的历史; 而对类群和地理采集完整度的评估结果表明，中国竹类标本的采集和整理工作仍任 重道远。模型模拟结果表明，温度限定了竹类植物两大分支各自的分布北界，水分对温带木本竹类分支(temperate woody bamboos, TWB)的限制作用比旧世界热带木本竹类分支(paleotropical woody bamboos, PWB)强, 而温度对PWB的限制性更强。 生态位模拟的结果进一步显示，中国温带和旧世界热带木本竹类两大分支的适生区出现了明显的分化，但在亚热带区域仍有 部分重叠。植物标本记录了特定类群在时间和空间上的分布格局, 相关的信息一方面可以促进物种灭绝风险评估、可持续利 用和综合保护，另一方面也可助力大尺度生物多样性分布格局及全球变化对多样性的影响研究。

关键词: 竹类植物; 馆藏标本; 采集现状; 完整度评估; 气候因子; 地理分布

许祖昌, 罗亚皇, 秦声远, 朱光福, 李德铢 (2021) 中国竹类植物馆藏标本现状与地理分布. 生物多样性, 29, 897-909. doi: 10.17520/biods.2020373. Xu ZC, Luo YH, Qin SY, Zhu GF, Li DZ (2021) Current status of herbarium specimens and geographical distribution of bamboos (Gramineae: Bambsusoideae) in China. Biodiversity Science, 29, 897-909. doi: 10.17520/biods.2020373.

\section{Current status of herbarium specimens and geographical distribution of bamboos (Gramineae: Bambsusoideae) in China}

Zuchang Xu ${ }^{(1,2}$, Yahuang Luo ${ }^{3}$, Shengyuan Qin ${ }^{1,2}$, Guangfu Zhu ${ }^{1,2}$, Dezhu Li ${ }^{\text {(D) } 1,2^{*}}$

1 Germplasm Bank of Wild Species, Kunming Institute of Botany, Chinese Academy of Sciences, Kunming 650201

2 Kunming College of Life Sciences, University of Chinese Academy of Sciences, Kunming 650201

3 Key Laboratory for Plant Diversity and Biogeography of East Asia, Kunming Institute of Botany, Chinese Academy of Sciences, Kunming 650201

\begin{abstract}
Aims: Herbarium specimens are important for taxonomic research. Analyses of these specimens are important for understanding their history, taxonomic status, and existing gaps in knowledge. In addition, such analyses allow for deeper insights into the distribution and classification of specific taxa using phylogenetic and niche modeling techniques. In most cases, identification of herbarium specimens is based on the reproductive traits. However, bamboo is a long-lived clonal plant that undergoes flowering followed by simultaneous death after a long-term growth period. As a result, most bamboo specimens only contain vegetative characters, and the information on reproductive traits remains sparse. As a result of this unique life history, bamboos are one of the most difficult taxa for taxonomic research.
\end{abstract}

收稿日期: 2020-09-21; 接受日期: 2021-03-05

基金项目: 国家自然科学基金(31670396)

* 通讯作者 Author for correspondence. E-mail: dzl@mail.kib.ac.cn 
Here, we aim to examine the status of collection of bamboo herbarium specimens in China and document existing biases. Furthermore, we also aim to evaluate the main drivers for the distribution of the two major clades of bamboos (temperate woody bamboos, TWB; paleotropical woody bamboos, PWB).

Methods: Here, we used collection data from the major herbaria of China to analyze the current collection and preservation status of bamboo specimens. The completeness of the collection was evaluated by the ratio and slope methods with respect to geographical and group deviations. In combination with climate data from WorldClim, we used model simulations to identify the main factors affecting the distribution of bamboo.

Results: The results from the analysis on collection information indicate that there is a great unevenness in the collection and conservation of bamboo specimens in domestic herbaria. These aspects are highly dependent on the vigor of research teams. Second, variation in the collection of bamboo specimens is a clear reflection of the history of plant taxonomy research in China. Additionally, the results from the assessment of taxa and the completeness of geographic collection indicate that much work still remains for the collection and collation of bamboo specimens in China. The analysis of model simulations showed that the distribution of the two major clades of bamboos in China is mainly limited by a low temperature. Moisture had a greater effect on the distribution of TWB than on PWB, while the effect of temperature was higher for PWB. Results from niche modeling further indicate that the PWB and the TWB in China have diverged in area use with only some overlap in subtropical areas.

Conclusions: Our study highlights the geographic distribution and taxa collecting biases in herbarium specimens of bamboos in China, as well as the significance of climate variables for the distributions of temperate and paleotropical woody bamboos. Our findings also indicate some poorly sampled areas, which should be preferential targets for future biodiversity surveys. Furthermore, as millions of digitalized herbarium specimens become available online and will play an important role in revealing large-scale diversity patterns. Such effort can improve the forecasts of the impacts of climatic change on the biodiversity.

Key words: bamboo; herbarium specimens; collection status; completeness assessment; climate factors; geographical distribution

竹类植物具有重要的经济和生态价值, 很早就 被人类认识和研究(McClure, 1966)。根据目前在国 际上广为接受的 APG IV (Angiosperm Phylogeny Group IV)系统, 竹亚科隶属于被子植物单子叶分 支禾本目禾本科, 是禾本科的 12 个亚科之一, 与早 熟禾亚科、稻亚科一起构成BOP (BambusoideaeOryzoideae-Pooideae)分支(GPWG, 2001; GPWG II, 2012; Soreng et al, 2017; Saarela et al, 2018)。近年来 的分子系统发育研究支持将竹亚科分为莪莉竹族 (Olyreae) 、青篱竹族 (Arundinarieae) 和策竹族 (Bambuseae) 3 个族, 它们又分别属于草本竹类分支 (herbaceous bamboos)、温带木本竹类分支(temperate woody bamboos, TWB) 和热带木本竹类分支 (tropical woody bamboos), 其中热带木本竹类又可 进一步分为旧世界热带木本竹分支 (paleotropical woody bamboos, PWB) 和新世界热带木本竹分支 (neotropical woody bamboos, NWB); 中国仅有旧世 界热带木本竹类和温带木本竹类(Kelchner \& BPG, 2013; Guo et al, 2019)。据最新统计, 全世界共有竹 类127属约1,680种(Clark \& Oliveira, 2018)。中国是 世界上竹类资源最丰富的国家, 其物种数、分布面
积、蓄积量等均居世界各国之首, 《中国植物志》 (Flora Reipublicae Popularis Sinicae, FRPS)和Flora of China (FOC)记载的竹类达34属534种( $\mathrm{Li}$ et al, 2006)。

竹类是公认的禾本科植物分类困难类群。究其 原因, 首先是竹类标本采集要求高, 过程较为繁琐, 一般需要地下茎、秆节、秆篷、分枝和完整的叶子 (包括叶鞘、叶舌、叶耳和叶片)等部位的标本, 缺少 某些关键性状(如秆等)会增加鉴定的难度和降低鉴 定的准确性, 因此很多植物标本采集者往往会忽视 竹类标本的采集(Soderstrom \& Young, 1983)。其次, 竹类植物具有特殊的生物学特性。长期以来, 植物 分类学基于繁殖器官的特征来描述和鉴别物种, 但 由于竹类特殊的开花习性, 绝大多数木本竹类均为 一次性开花, 开花后死亡, 且开花周期具有异质性 (3-120年) (Janzen, 1976), 采集的营养体标本很难 与常常仅包括繁殖体的模式标本进行对比鉴定。因 此, 竹类物种的鉴定问题以及较少的标本记录对其 研究形成了极大的阻碍, 并在很大程度上制约着竹 类植物的培育、利用和保护。

植物标本是植物研究者在长期的科研活动中 
采集和保存的凭证材料, 体现着人类对某个类群的 认识, 也是自然遗产的实体记录; 信息完备的植物 标本是物种分类、分布及系统演化等学科的重要资 料(Bridson \& Forman, 1998), 其携带的信息有着重 要的研究价值。最早的标本主要服务于物种发现和 志书编写, 随着标本数目增加和相关信息的数字化, 基于植物标本开展的研究形式也越来越多样化。如 张玉雪等(2018)利用国家标本资源共享平台 (National Specimen Information Infrastructure, NSII, http://www.nsii.org.cn)的数据分析了我国杜鹃花标 本的采集现状, 揭示了我国杜鹃花科植物物种丰富 度的分布状况及影响因素; He等(2019)基于蓝钟花 属(Cyananthus)和报春花属(Primula) 10 个物种馆藏 标本记录的分布信息, 结合气候数据, 估算了其历 史分布区的范围和气候变化对当下分布区的影响, 并预测了物种未来潜在分布区的变化趋势。此外, 通过标本记录也可对植物类群的地理采集偏差情 况及其原因进行评估和探索, 如阳文静(2013)利用 近千万条分布数据评估了中国植物标本的地理采 集偏差并探讨其原因; 王凯莉等(2018)利用国家标 本资源共享平台的数据对全国蓄薇科的采集情况 进行了评估, 发现标本记录可信度好, 具有较好的 利用价值; 蓄微科植物的标本采集地主要集中在西 南地区, 并且在偏远地区的采集强度显著偏低。另 一方面, Zeng等(2018)利用二代测序技术提取了馆 藏80年的标本DNA并获取了其叶绿体基因组和核 糖体DNA大亚基数据, 为植物系统发育和DNA条 形码的研究打开了一扇新的窗户。

对于竹类这样一个有巨大价值但研究困难的 类群, 关于其馆藏标本及地理分布的研究却鲜见报 道。本研究利用中国竹类植物馆藏标本的采集信息, 以省级(直辖市、自治区等)行政区划为基本单元, 分 析了中国竹类植物的采集现状和采集偏差; 同时结 合气候数据, 对中国竹类的地理分布状况进行研究, 以期为今后的竹类植物标本采集和物种保护等工 作提供基础资料。

\section{材料与方法}

\section{1 数据来源}

本研究的数据来源主要包括: (1)国家标本资源 共享平台; (2)中国数字植物标本馆(Chinese Virtual Herbarium, CVH, http://www.cvh.org.cn); (3)竹类植
物标本较为集中的各标本馆实地收集, 如中国科学 院西双版纳热带植物园植物标本馆(HITBC)、中国 科学院华南植物园植物标本馆(IBSC)、中国科学院 昆明植物研究所标本馆(KUN)、南京大学生命科学 学院植物标本室 $(\mathrm{N})$ 、江苏省中国科学院植物研究所 标本馆(NAS)、中国科学院植物研究所植物标本馆 (PE)、西南林业大学林学院植物标本室(SWFC)和中 山大学生命科学学院生物博物馆植物标本室(SYS); (4)相关文献记载(王仁赞等, 2012)。

\section{2 数据标准化}

随着植物分类学研究的不断深入, 植物科学名 称的使用往往会发生变化; 且不同的采集者对标本 采集信息的记录风格和完整度不一, 造成了现有标 本信息不全乃至含混。因此, 本研究对获得的标本 数据进行了标准化处理, 具体方法如下: (1)利用网 站Taxonomic Name Resolution Service v4.1 (TNRS, http://tnrs.iplantcollaborative.org)对获得的标本名称 状态进行异名剔除和标准化(Boyle et al, 2013), 仅 保留接受名(Accepted状态)且准确率得分在 0.9 以上 的数据; (2)剔除采集地点缺失和在中国行政区以外 的采集记录; (3)对于采集地点记录不全的数据(如 仅包括小地名), 则通过百度地图和Google Earth (Version 7.1.8.3036)查询标本上记录的地名字段, 尽可能补全数据。在此基础上, 依据 $\mathrm{CVH}$ 网站中的 中国早期标本采集地名考(https://www.cvh.ac.cn/top ics/counties.php)将变更的地名进行校验。数据标准 化完成后, 使用Google Earth (Version 7.1.8.3036)查 询标本采集点对应的经纬度信息, 并利用ArcGIS 10.7 绘制分布图。

\section{3 复份标本的处理}

《国际藻类、菌物和植物命名法规》第八条规 定: 一个采集的多个制备, 如果未注明其是同一份 标本的组成材料时, 则这些制备互相构成复份标本 (Turland et al, 2018)。一份完整的标本通常包含植物 的各部分器官, 但由于竹类植物的特殊性, 各部位 的材料往往难以展示在同一张台纸上, 而该类群的 标本在采集和装订过程中很少注明是复份标本还 是属于同一份标本的不同部分。因此, 为了研究的 方便, 本研究将采集号、采集人、采集时间以及采 集地点完全相同的标本视为一份标本, 只保留其中 一条标本信息。 


\section{4 采集完整度的评估}

标本采集偏差是评价标本采集完整度的重要 参数, 具体可分为两种: 一是受地理、交通、气候 等条件和采集人的记录习惯等因素的影响, 在采集 过程中会出现采集地点不均衡, 部分地区遗漏或采 集数量过少等影响数据完整性的情况, 即采集地点 偏差; 二是由于采集对象的类群特点、分布频率、 物候和采集难易程度不同等, 导致采集者对某些类 群重复采集, 而某些类群采集很少, 即采集类群偏 差。本研究利用比值法和斜率法分别对其进行评估, 并比较了这2种方法评估结果的差异。

(1)比值法。该方法利用观察丰富度和估计丰富 度的差值与估计丰富度的比值大小来评估采集的 完整度, 是生物多样性领域常用的方法之一。估计 物种的丰富度, 常用的有 Chao, Jackknife 和 Bootstrap等模型, 其中Chao 1 估计量最早由Chao于 1984年提出, 其基本假设认为如果在一个群体中随 机抽样, 当稀有的物种(采集份数仅为1)依然不断被 发现时, 则表明还有稀有的物种没有被发现; 直到 所有物种至少被抽到 2 次(采集份数至少为2), 则表 明不会再有新的物种被发现(Chao, 1984)。其计算公 式为:

$$
\text { Chao } 1=S_{o b s}+F_{1}{ }^{2} / 2 F_{2}
$$

其中, $S_{o b s}$ 表示样本中观察到的物种数, $F_{1}$ 表示只有 1 个个体的物种数, $F_{2}$ 表示只有 2 个个体的物种数。

本文采用标本实际记载物种数和Chao 1 估计量 的差值与Chao 1估计量的比值来评估竹类各属标本 以及中国各省级行政区的采集完整度, 即采集完整 度 $=$ (观测值 - 理论值)/理论值, 比值越小代表采 集越不完整。根据实际情况, 在本研究中我们限定 比值 $<-0.5$ 时为采集不完整; $[-0.5,-0.3]$ 为采集较完 整; $>-0.3$ 为采集完整。

(2)斜率法。该方法基于物种累积曲线(species accumulation curve, SAC), 当抽样数目达总标本数 的 $90 \%$ 时对应的曲线斜率作为采集完整度的判断标 准(Tittensor et al, 2010; Chu et al, 2014)。物种累积曲 线最早是生态学中用于估计物种数量的一种方法, 原理是当采集的标本逐渐增多时, 新种发现的速率 就会下降, 如果标本数量无限大时, 物种累积曲线 就趋近于物种库总数。

本研究将竹类各属(采集类群偏差)以及中国各 省级行政区(采集地点偏差)的全部标本记录进行随
机抽样并统计每次获得的物种数目, 抽样数目以总 标本数的 $1 \%$ 为梯度依次递增, 并且每个数目进行 10,000 次重抽样。此后, 以每次抽样的标本数目作 为横坐标, 以 10,000 次抽样的平均物种数为纵坐标 分别绘制各属以及各省区的物种累积曲线，并计算 抽样数目为总标本数 $90 \%$ 时曲线所对应的斜率。当 曲线斜率值接近 0 时，表明该属或该地区的采集较 完整，当斜率值接近1时，则表明采集不完整，可能 有新种存在。本研究以 0.005 作为斜率阈值对采样完 整度进行评估，当斜率 $\geq 0.005$ 时表示采集不完整， 反之则表明采集完整。

\section{5 气候因子变量数据筛选}

从全球气候数据库WorldClim (http://www.worl dclim.org/)下载ACCESS1-0模型中的19个环境气候 图层数据(Hijmans et al, 2005), 选择最大精度(30") 进行后续分析。由于变量之间的多重共线性会导致 物种分布模型的过度拟合, 本研究剔除高度相关 $(|\mathrm{r}|$ $\geq 0.80$ )的环境变量(Menard, 2001, 崔相艳等, 2016), 按照生物学意义最终保留年均温 (annual mean temperature, Bio1)、最热月最高温(max temperature of warmest month, Bio5)、最冷月最低温 (min temperature of the coldest month, Bio6)、年温度变化 范围(temperature annual range, Bio7)、年均降水量 (annual precipitation, Bio12)、最湿月降水量 (precipitation of wettest month, Bio13)、最干月降水 量(precipitation of driest month, Bio14)和降水量季 节性变异系数(coefficient of variation of precipitation seasonality, Bio15)共8个变量进行生态位模拟, 分 析影响竹类植物分布状况的主要环境因子。由于本 研究所涉及的区域仅包括中国境内, 故通过ArcGIS 的Extract工具从世界环境图层中提取中国范围内的 环境图层数据。

\section{6 不同竹类分支的MaxEnt模型分析}

将获得的中国竹类标本数据按照最新的竹亚 科系统学结果分成旧世界热带木本竹类和温带木 本竹类 2 个分支(Kelchner \& BPG, 2013), 把竹类标 本的分布点经纬度信息和环境图层导入MaxEnt软 件(Phillips et al, 2006)。在模型分析中, 最大迭代次 数设置为 10,000 , Bootstrap 重复运算 20 次, 启用 random seed、勾选绘制响应曲线(response curves) 和刀切法(Jackknife检验)来分析影响竹类分布状况 的环境变量, 其中 $25 \%$ 的数据作为训练数据 
(training data), $75 \%$ 的数据用于建立模型。MaxEnt 软件会自动绘制 ROC 曲线 (receiver operating characteristic curve)并计算曲线下的面积AUC (areas under the receiver operating characteristic curves)来 对模型的拟合效果进行评价。当AUC $<0.5$ 时, 表明 模型的预测效果很差, 在0.6-0.9之间表明模型预测 效果一般, AUC > 0.9说明模型预测的效果很好(王 运生等, 2007; Liu et al, 2005。本文模型拟合的AUC 均> 0.9 。

\section{2 结果}

\section{1 我国竹类植物标本基本情况}

初步统计表明, 中国竹类植物标本藏量为 51,194份, 本研究获得其中44,694份(87\%)标本的信 息。通过异名处理后, 剩余35,024条有效信息; 剔除 采集地点缺失数据和在中国行政区以外的采集记 录, 剩余30,156份标本。统计发现, 中国共有108家 单位的标本馆(室)收藏有竹类标本, 馆藏量从 1-13,369份不等, 其中南京大学生命科学学院植物 标本室的竹类植物标本数量最高, 为 13,369 份, 占 全国总馆藏量的1/4; 剔除复份标本后, 发现馆藏量 排名前 15 位的标本馆保存了 $86 \%$ 的竹类标本 (图 1A)。除黑龙江省、吉林省和澳门特别行政区外, 中 国各省级行政区域均有竹类标本的采集记录, 但新 疆维吾尔自治区、内蒙古自治区和辽宁省的馆藏标 本均采自栽培竹类。从各省区的标本数量来看, 馆 藏竹类植物标本的采集主要集中于长江以南地区, 采集超过 1,000 份的省区有 10 个, 其中以云南最多, 浙江次之, 这两省采集的标本份数均超过 4,000 份, 占中国竹类标本的1/3 (图2)。而长江以北地区的馆 藏竹类植物标本主要采集于黄河以南区域, 黄河以 北地区竹类标本记录稀少, 如青海省竹类标本不足 10份。

最新的文献记载中国产竹类38属(Vorontsova, 2016), 但标本记录仅有33属, 有 5 个属在共享数据 库中没有标本, 包括须弥䈶竹属(Himalayacalamus) (耿伯介, 1983)、多枝竹属(Holttumochloa, 我国新分 布属) (Wong, 1993)、纪如竹属(Hsuehochloa, 2018 年发表的新属) (Zhang et al, 2018)、冷箭竹属 (Sarocalamus, FRPS 中被处理为异名) (Stapleton, 2004)和华箬竹属(Sasamorpha, FRPS中被处理为异 名) (Nakai, 1931), 这些类群标本数据的缺失主要是
相应标本馆未能对标本鉴定信息进行适时更新造 成的。从属级水平看, 平均标本数大于 10 份的属有 21 个, 仅占所有属的 $62 \%$ (表1); 从物种水平看, 馆 藏标本物种的平均采集量为 30.5 份, 且各物种的实 际采集量间存在着很大差异。55\%的物种采集量不 足 10 份, 其中 $15 \%$ 的物种仅采集了 1 份标本; 仅有 $7 \%$ 的物种采集量在100份以上(图1B), 如湖南刚竹 (Phyllostachys carnea)采集量仅有1份, 而同属的桂 竹(P. bambusoides)采集量则高达910份。

对竹类标本的采集月份进行统计, 结果显示标 本采集工作主要集中于春夏两季, 其采集量占全部 标本的73\%, 而冬季最少, 仅占总量的7\% (图1C)。 对采集年份的统计结果表明, 标本采集量呈现 4 个 明显的波峰(图1D)。结合中国禾本科等研究历史, 我们将采集时间段划分为 5 个阶段：1934年以前为 第一阶段, 以国外采集者为主, 采集量占16\%; 第 二阶段为1934-1959年(FRPS启动前), 采集量占 13\%; 第三阶段为1959-1996年(FRPS启动后到竹亚 科分册完成), 采集量最多, 采集量占55\%; 第四阶 段为1996-2006年(FRPS 竹亚科分册完成到FOC竹 亚科部分完成), 采集量仅占 $2 \%$; 第五阶段为2006 年至今(FOC竹亚科部分完成后), 采集量占 $14 \%$ (图 $1 \mathrm{E})$ 。统计标本所处的生活史阶段, 发现中国馆藏竹 类植物标本主要以营养性状为主, 比例高达 $69 \%$, 仅有 $1 \%$ (将近 1,000 份)的标本同时具有花果性状, 分布在27属124竹种中, 而温带木本竹类的具花标 本数量远高于旧世界热带木本竹类, 且有花标本主 要采集于FRPS竹亚科分册出版(1996年)之前。

\section{2 采集完整度评估}

物种丰度观测值和预测值最大的均为云南省, 远超其他省份; 位于黄河以北的各省区观测值和预 测值都偏小, 其中内蒙古、宁夏和青海3省标本采集 总数非常少, 均不超过10份(图2)。各省市标本的观 测值和预测值的差值与预测值的比值在 -0.610 到 0 之间波动, 平均值为 -0.299 , 其中安徽、北京和台湾 为采集不完整的省区 (其中台湾极可能是因为本研 究未能收录其相关标本馆数据之故); 而甘肃、广 东、海南、河北、山西、四川和西藏为采集较完整 区域, 其余地区为采集完整区域。比值大小和标本 采集份数的相关性分析结果表明二者之间的相关 性较弱(附录 $1 \mathrm{~A}, R^{2}=0.21$ )。此外, 地理邻近区域的 采集情况也参差不齐, 如湖南和湖北彼此接壤, 但 
A

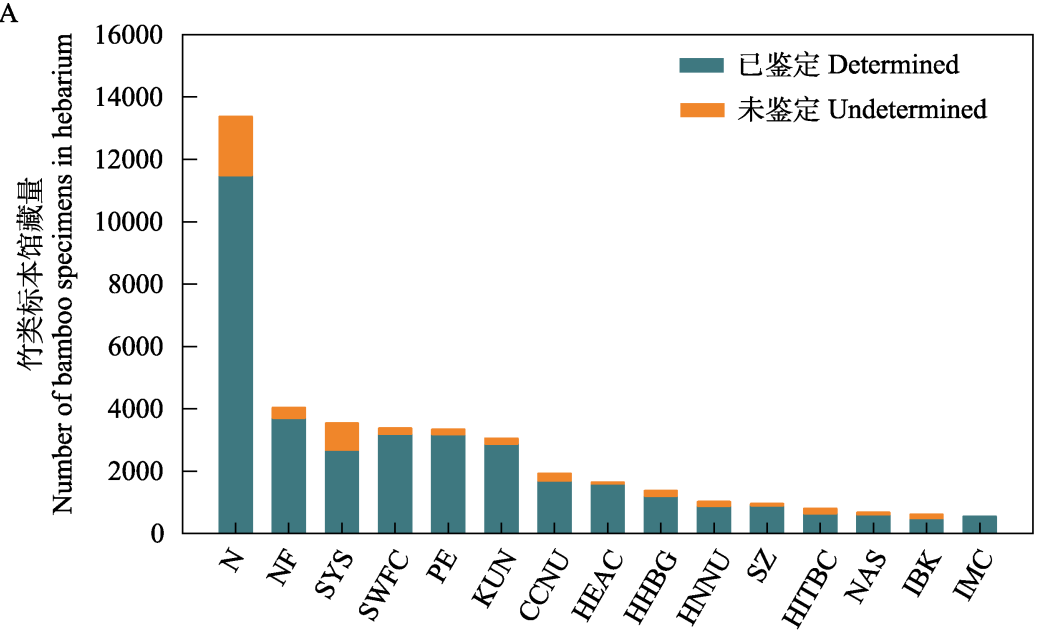

标本馆 Hebaria
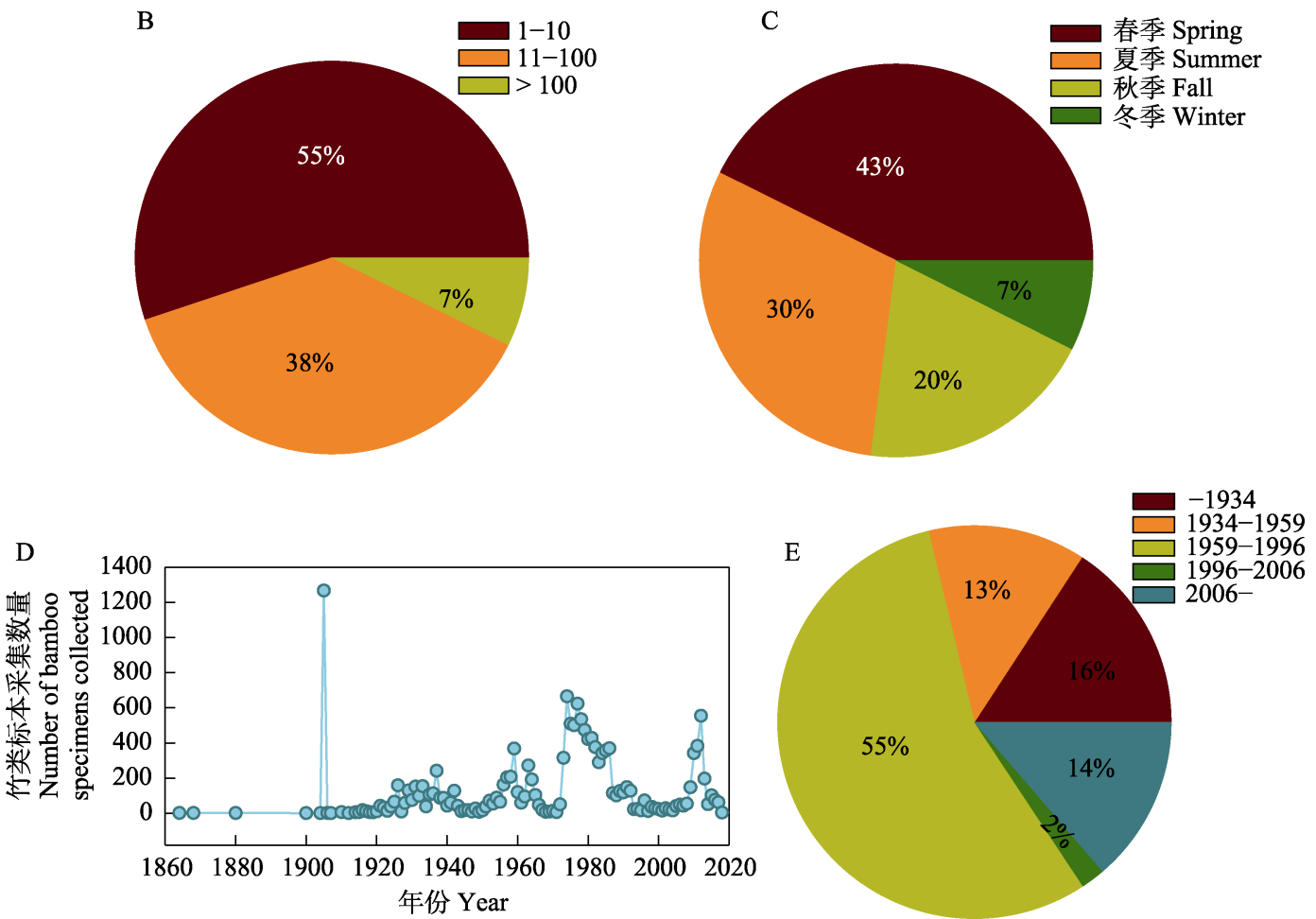

图1 中国馆藏竹类标本数据统计。A: 中国馆藏竹类植物标本数量前15的标本馆馆藏量(标本馆代码见附录2); B: 国产竹类 标本采集份数统计; C: 国产竹类标本采集季节统计; D: 国产竹类标本采集年份统计; E：国产竹类各时期标本采集量统计。

Fig. 1 Statistical depiction of bamboo specimen data collected in China. A, Herbarium statistics of top 15 herbaria with bamboo specimens collected in China (The code of the herbarium is shown in Appendix 2); B, Status of bamboo specimens in China at the species level; C, Season of collection of bamboo specimens in China; D, Year of collection of bamboo specimens in China; E, Relative proportions of bamboo specimens collected at various periods in China.

标本采集数量和物种数却都存在较大差异。斜率法 结果表明，安徽、北京、海南、河北、内蒙古、青 海、上海、山西、台湾和西藏为采集不完整区域(其 中台湾可能是受本研究收集数据影响), 其余省区 采集完整(表2)。与比值法相比，在标本采集总量大 的情况下, 二者结果差异不明显。
通过比值法评估各属的采集完整度时，由于以 悬竹属(Ampelocalamus)为代表的 23 个属的物种标 本数据量不符合计算条件, 无法计算Chao 1 值。剩 余的 15 个属中仅有赤竹属 $($ Sasa $)$ 的比值 $<-0.5$, 为采 集不完整的属, 茶杆竹属(Pseudosasa)为采集较完 整的属, 其余13个属为采集完整的属。值得注意的 


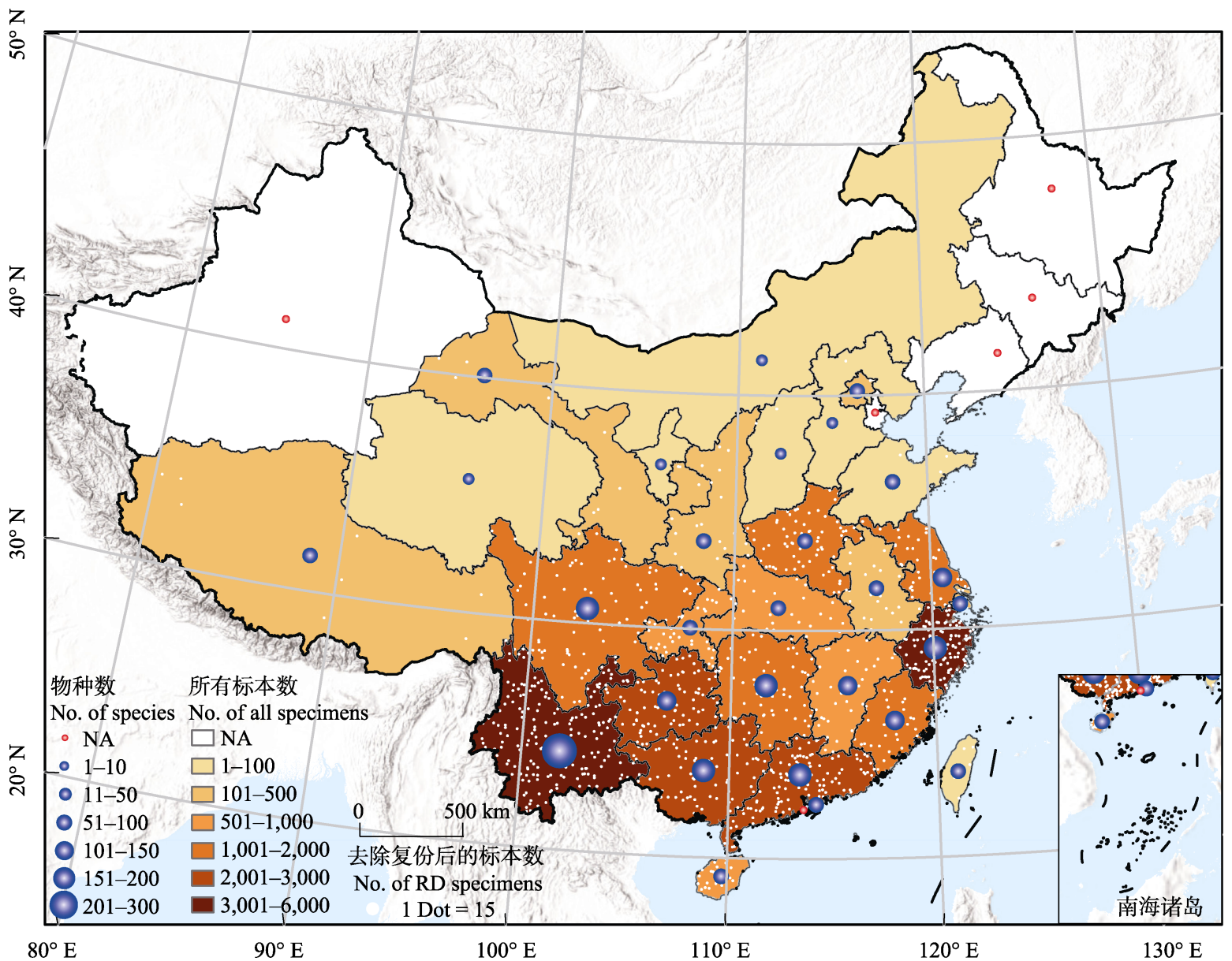

图2 中国各省级行政区竹类标本采集份数和物种数的分布。白色圆点表示去除复份标本后的标本数量, 每个白点代表15份。 Fig. 2 Distribution of bamboo specimens and species in different provinces of China. The white dots indicate the number of specimens that removing duplicate (RD) specimens. Each white dot represents 15 specimens.

是, 仅有赤竹属和茶秆竹属两个属的Chao 1 估计量 超过了文献记载数, 其余各属的估计量均小于文献 记载数(表1)。比值大小和各属标本采集份数的相关 性分析结果表明二者之间的相关性较弱(附录1B, $\left.R^{2}=0.006\right)$ 。斜率法评估的结果显示悬竹属、梨藤 竹属(Melocalamus)、少穗竹属(Oligostachyum)、苦 竹属(Pleioblastus)、茶秆竹属、冷箭竹属、赤竹属、 业平竹属(Semiarundinaria)、泰竹属(Thyrsostachys) 等9个属采集不完整。比较发现, 在标本采集量不足 时, 两种方法都存在较大误差甚至失效, 但斜率法 的适用性优于比值法。

\section{3 气候因子对竹类植物地理分布的影响}

根据竹类植物馆藏标本经纬度信息绘制竹类 分布图, 发现旧世界热带木本竹类分布于长江以南 地区，而温带木本竹类可分布到黄河流域，且黄河 以北还有零星分布(图3A)。MaxEnt模型分析的刀切
法结果显示(图3B), 旧世界热带木本竹类的分布受 最冷月最低温的影响最大, 其次是年温度变化范围, 而水分条件的影响较小; 温带木本竹类的分布主要 受年均降水量的影响, 其次是最冷月最低温。对比 发现, 最冷月最低温是影响两大分支分布的共同影 响因素, 水分对温带木本竹类的影响比对旧世界热 带木本竹类明显, 而温度对旧世界热带木本竹类的 限制性更强。MaxEnt模型模拟结果表明，旧世界热 带木本竹类同等检测特异性和敏感性的阈值(equal test sensitivity and specificity cloglog threshold)为 0.4813 , 其适生区域主要为我国珠江流域以南的地 区(图4绿色区域); 温带木本竹类同等检测特异性 和敏感性的阈值为 0.4817 , 其适生区在长江流域地 区(图4红色部分); 两者之间存在一带状的重叠区, 为两者的共同适生区(图4黄色区域), 值得注意的是 云南大部分区域和四川盆地均为其适生重叠区域。 
表1 中国国产竹类各属标本采集情况统计与分析

Table 1 Statistical analysis on herbarium specimens of bamboos in China at the genus level

\begin{tabular}{|c|c|c|c|c|c|c|c|}
\hline $\begin{array}{l}\text { 属 } \\
\text { Genus }\end{array}$ & $\begin{array}{l}\text { 文献记录物种数 } \\
\text { Number of species } \\
\text { based on literature }\end{array}$ & $\begin{array}{l}\text { 标本记录物种数 } \\
\text { Number of species } \\
\text { based on specimens }\end{array}$ & $\begin{array}{l}\text { 标本数 } \\
\text { Specimens }\end{array}$ & $\begin{array}{l}\text { 每个物种平均标本数 } \\
\text { Mean specimens per species }\end{array}$ & Chao 1 & $\begin{array}{l}\text { 比值 } \\
\text { Ratio }\end{array}$ & $\begin{array}{l}\text { 斜率 } \\
\text { Slope }\end{array}$ \\
\hline 酸竹属 Acidosasa & 10 & 6 & 32 & 5.3 & 7 & -0.143 & 0.003 \\
\hline 悬竹属 Ampelocalamus & 14 & 9 & 98 & 10.9 & - & - & 0.007 \\
\hline 䈤竹属 Bambusa & 90 & 62 & 2,188 & 35.3 & 65 & -0.046 & 0.003 \\
\hline 巴山竹属 Bashania & 6 & 0 & 0 & - & - & - & - \\
\hline 单枝竹属 Bonia & 4 & 3 & 35 & 11.7 & 3 & 0.000 & 0.000 \\
\hline 空竹属 Cephalostachyum & 7 & 5 & 91 & 18.2 & - & - & 0.000 \\
\hline 方竹属 Chimonobambusa & 38 & 21 & 926 & 44.1 & 21 & 0.000 & 0.000 \\
\hline 香竹属 Chimonocalamus & 10 & 11 & 263 & 23.9 & - & - & 0.000 \\
\hline 牡竹属 Dendrocalamus & 37 & 31 & 1,146 & 37.0 & 33 & -0.061 & 0.002 \\
\hline 镰序竹属 Drepanostachyum & 4 & 1 & 2 & 2.0 & - & - & 0.000 \\
\hline 箭竹属 Fargesia & 87 & 56 & 831 & 14.8 & 59 & -0.051 & 0.003 \\
\hline 铁竹属 Ferrocalamus & 2 & 1 & 22 & 22.0 & - & - & 0.000 \\
\hline 贡山竹属 Gaoligongshania & 1 & 1 & 5 & 5.0 & - & - & 0.000 \\
\hline 井冈寒竹属 Gelidocalamus & 12 & 8 & 76 & 9.5 & 8 & 0.000 & 0.003 \\
\hline 巨竹属 Gigantochloa & 15 & 9 & 55 & 6.1 & 9 & 0.000 & 0.003 \\
\hline 须弥䈗竹属 Himalayacalamus & 2 & 0 & 0 & - & - & - & - \\
\hline 多枝竹属 Holttumochloa & 1 & 0 & 0 & - & - & - & - \\
\hline 纪如竹属 Hsuehochloa & 1 & 0 & 0 & - & - & - & - \\
\hline 箬竹属 Indocalamus & 32 & 20 & 1,317 & 65.9 & 22 & -0.091 & 0.002 \\
\hline 大节竹属 Indosasa & 16 & 15 & 378 & 25.2 & - & - & 0.000 \\
\hline 梨藤竹属 Melocalamus & 6 & 3 & 72 & 24.0 & - & - & 0.006 \\
\hline 梨竹属 Melocanna & 1 & 1 & 8 & 8.0 & - & - & 0.000 \\
\hline 新小竹属 Neomicrocalamus & 1 & 1 & 8 & 8.0 & - & - & 0.000 \\
\hline 少穗竹属 Oligostachyum & 18 & 8 & 61 & 7.6 & - & - & 0.005 \\
\hline 刚竹属 Phyllostachys & 61 & 52 & 5,868 & 112.8 & 53 & -0.019 & 0.001 \\
\hline 苦竹属 Pleioblastus & 18 & 15 & 778 & 51.9 & - & - & 0.006 \\
\hline 茶秆竹属 Pseudosasa & 17 & 14 & 577 & 41.2 & 22 & -0.364 & 0.006 \\
\hline 泡竹属 Pseudostachyum & 1 & 1 & 65 & 65.0 & - & - & 0.000 \\
\hline 冷箭竹属 Sarocalamus & 3 & 0 & 0 & - & - & - & - \\
\hline 赤竹属 Sasa & 9 & 10 & 83 & 8.3 & 28 & -0.643 & 0.013 \\
\hline 华箬竹属 Sasamorpha & 3 & 0 & 0 & - & - & - & - \\
\hline 箅筫竹属 Schizostachyum & 13 & 9 & 368 & 40.9 & 9 & 0.000 & 0.000 \\
\hline 业平竹属 Semiarundinaria & 5 & 3 & 12 & 4.0 & - & - & 0.021 \\
\hline 倭竹属 Shibataea & 7 & 7 & 110 & 15.7 & - & - & 0.003 \\
\hline 唐竹属 Sinobambusa & 10 & 8 & 146 & 18.3 & - & - & 0.002 \\
\hline 符竹属 Thamnocalamus & 2 & 1 & 7 & 7.0 & 1 & 0.000 & 0.000 \\
\hline 泰竹属 Thyrsostachys & 2 & 2 & 23 & 11.5 & - & - & 0.010 \\
\hline 玉山竹属 Yushania & 70 & 51 & 609 & 11.9 & 53 & -0.038 & 0.003 \\
\hline 总计 Total & 636 & 445 & 16,334 & 36.7 & 476 & -0.065 & 0.003 \\
\hline
\end{tabular}

\section{3 讨论}

本研究收集整理了全国竹类植物馆藏标本的 采集信息，首先将其标准化处理后对标本的基本信 息进行分析，再利用比值法和斜率法对标本的采集 类群偏差和采集地点偏差进行评估, 最后基于
MaxEnt模型对国产竹类两大分支的适生区和影响 其分布的主要环境因子进行评估。

\section{1 竹类标本馆藏历史及现状分析}

统计分析发现, 国内标本馆对竹类标本的收集 和保藏存在很大的不均衡性, 竹类标本主要收藏于 南京大学生命科学学院植物标本室等 15 个标本馆 
表2 中国各省级行政区竹类植物标本采集情况统计

Table 2 Statistical analysis of herbarium specimens of bamboos in different provinces of China

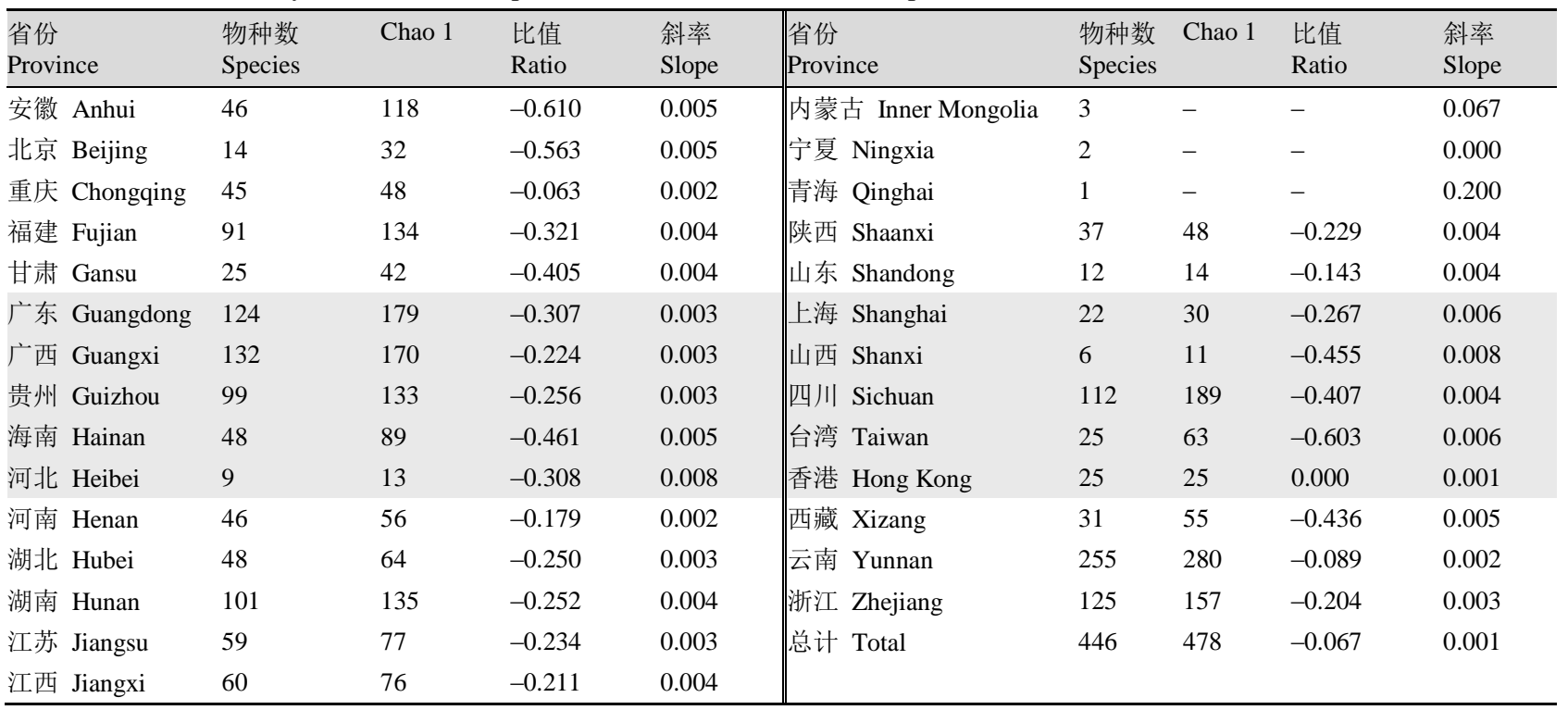
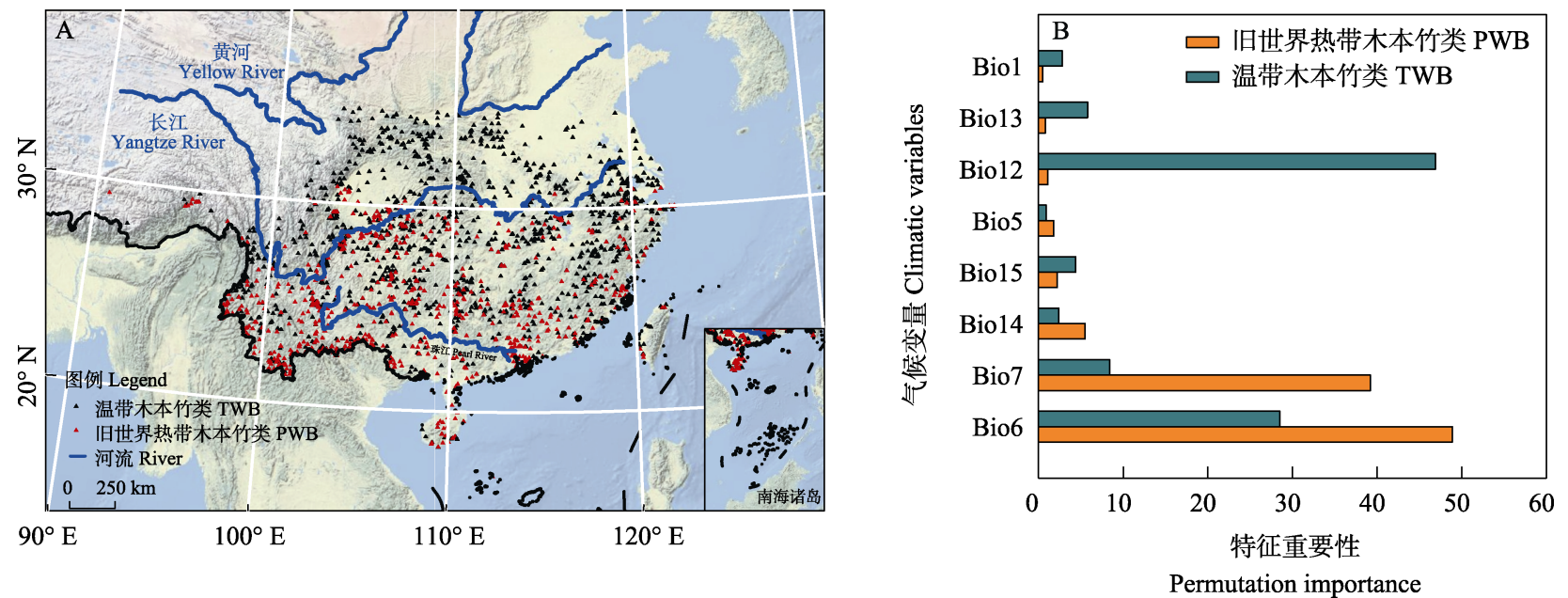

图3 国产竹类地理分布图(A)及影响因子重要性(B)。Bio1: 年均温; Bio5: 最热月最高温; Bio6: 最冷月最低温; Bio7: 年温 度变化范围; Bio12: 年均降水量; Bio13: 最湿月降水量; Bio14: 最干月降水量; Bio15: 降水量季节性变异系数。

Fig. 3 Distribution map of bamboos in China (A) and permutation importance of the climatic variables (B). PWB, Paleotropical woody bamboos; TWB, Temperate woody bamboos; Bio1, Annual mean temperature; Bio5, Max temperature of warmest month; Bio6, Min temperature of the coldest month; Bio7, Temperature annual range; Bio12, Annual precipitation; Bio13, Precipitation of wettest month; Bio14, Precipitation of driest month; Bio15, Coefficient of variation of precipitation seasonality.

内。究其原因, 首先这些标本馆在不同时期均有研 究团队开展过竹类相关研究, 积累了大量的研究材 料或凭证标本; 其次竹类标本采集专业性强, 分类 鉴定困难, 没有专门从事竹类研究人员的标本馆一 般不会或很少保存竹类标本。南京大学是FRPS竹亚 科分册完成前我国竹类植物分类研究的中心, 耿以 礼教授和耿伯介教授分别是我国禾本科和竹亚科 研究的开拓者, 耿伯介教授和王正平教授是FRPS 竹亚科分册的卷编辑。通过采集信息我们还发现标
本采集量的变化与团队的发展密切相关, 在收藏的 类群上与专家研究的类群和当地的资源均有很强 的相关性。基于此, 我们认为竹类标本的馆藏过于 集中, 这一方面极大地方便了该类群的研究者, 使 其从少数几个标本馆中即可获得全国大量竹类植 物的分类与分布信息; 但另一方面也容易产生偏向 性, 使本来就具有较高入门标准的竹类分类学研究 更加边缘化和专业化。

将竹类标本采集的阶段性特征放到中国近代 


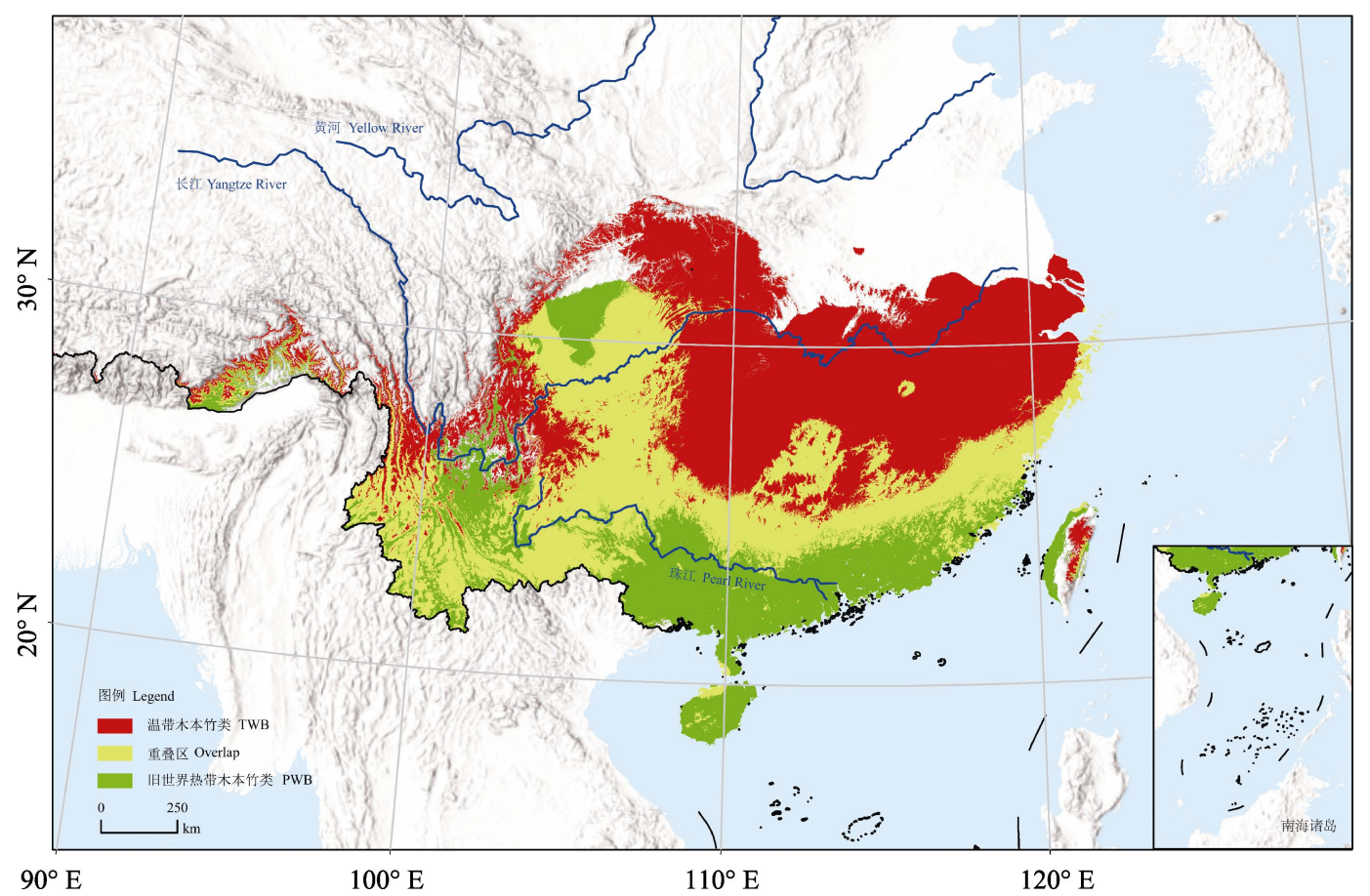

图4 MaxEnt模型对国产竹类高适生区的模拟结果

Fig. 4 Simulation results of the MaxEnt model of suitable areas for bamboos in China. PWB, Paleotropical woody bamboos; TWB, Temperate woody bamboos.

植物分类学研究的历程中, 我们发现竹类标本的采 集很好地代表了国内植物分类学研究的历史阶段。 首先, 在鸦片战争之后, 西方的植物采集者活跃于 中国各地开展采集活动和研究工作, 如莫古礼( F. M. McClure)等。其次, 20世纪以来, 随着第一代中 国植物学研究机构的建立, 不少类群(包括禾本科 在内)开始了由中国植物学者主导的研究工作, 并 逐渐积累植物标本, 其中耿以礼教授1934年学成归 国, 专注于中国禾本科的研究。新中国成立后, 启 动了植物志书的编纂项目, 标本采集和收藏活动蓬 勃开展, 逐渐形成目前的规模和馆藏状况。随后在 FRPS 和FOC等志书编纂完成之后, 标本采集热度 降低, 采集量明显减少。最近十余年, 随着分类学 研究进入分子生物学时代, 发现了研究中存在的诸 多问题, 需要继续采集标本, 同时分子生物学研究 也需要采集凭证标本，因此标本采集的热度又逐渐 恢复, 采集量逐年增加。对竹类标本采集史的梳理 为我们认识中国植物分类学研究的历程提供了一 个生动的例证。

对比文献记录和标本记录的属种信息，我们发 现两者之间存在较大差异。通过文献查证和实地考 察之后, 可将差异归结于以下两个原因: 一是部分
竹类标本还未实现数字化和数据共享, 如四川农业 大学都江堰分校竹标本室保存有易同培教授等人 收藏的 4,500余份标本, 多为高山竹类且包含许多 模式标本，但目前尚未进行数字化; 中国科学院华 南植物园植物标本馆保存的 2,000 余份竹类标本也 仅有151份标本信息公布在网络共享平台上; 二是 由于许多竹类物种的建立与分类变动，其标本信息 未及时更新, 如研究发现国产锐药竹属 (Oxytenanthera) 物种均应归类到巨竹属 (Gigantochloa)中(耿伯介, 1984)。标本是植物研究者 积累的宝贵财富，只有得到合理运用才能发挥其最 大的价值。国家标本资源共享平台致力于标本数字 化和资源共享，其重要性已逐步显现。首先，各标 本馆在运行过程中应该充分利用这些平台资源，这 不仅能提高标本的使用效率，也更有利于标本价值 的提升; 其次, 标本数字化是一个持续不断的过程, 馆藏量的逐年增加和与时俱进的分类修订，使得共 享平台需要建立一套行之有效的数字化信息管理 系统, 以促进标本数字化信息的实时更新。通过这 些工作, 才能使新的分类学研究成果及时体现在标 本信息上, 促进分类学成果的运用和分类学知识的 传播。 
杨永(2012)在分析中国植物标本馆馆藏规模时 引用了Baum的估算结果, 认为全球高等植物各物 种的标本采集量平均为 952 份, 笔者根据 NYBG (http://sweetgum.nybg.org/science/ih/) 网站提供的数 据估计其平均值已超过3,000份, 但目前国产竹类 植物每种的平均标本采集量约为30份, 其馆藏量远 远低于世界平均水平。另一方面, 营养体和繁殖体 齐全的竹类标本仅占标本总量的 $1 \%$, 且超过 $69 \%$ 的 标本仅有营养体标本。该现象在有花植物的收集中 颇为独特, 主要原因是竹类植物有花标本常常难以 获得。由于FRPS等志书研究的需要, 中国竹类植物 研究独创性地采用营养体标本作为凭证标本, 并据 此描述了大量新种。

\section{2 采集完整度分析}

从采集地点偏差评估结果来看, 比值法和斜率 法虽然没有得到完全一致的结果, 但也都表明大部 分省区采集完整度高。我们认为, 以省级行政区为 研究单位虽然较为粗放, 结论稍显粗粮, 但仍可以 为将来的竹类标本采集提供一些宏观指导。从采集 类群偏差评估结果来看, 采集主要集中在少数几个 常见属内, 平均标本数大于 10 份的属有 21 个, 仅占 所有属的 $62 \%$, 部分属标本采集量不足, 导致Chao 值法和斜率法存在较大误差。对比文献记载数、标 本记载数和Chao 1 估计量, 我们认为竹类标本采集 在属级水平存在明显的偏好性和不完整性。两种方 法在采集地点偏差和采集类群偏差的评估中没有 得出一致的结论, 从各自的理论依据来看, 两种方 法都会受到其他变量的影响, 斜率法容易受到采集 物种数和标本数的影响, 而比值法对稀有物种数更 加敏感。当标本采集量过少时, 两种方法都存在较 大误差, 但在标本采集量充足时, 两种方法得到的 结果差异不大。综合两种方法的评估结果可以看出, 国产馆藏竹类植物标本的采集整理工作任重道远。 我们需要综合运用两种方法得出的结果, 重点关注 采集不完整的区域和属, 并加大采集保藏和鉴定工 作的力度。

\section{3 适生区模拟分析}

基于标本的采集信息, 在最新分子系统学框架 的指导下, 我们绘制了国产竹类植物两大分支的分 布图, 发现其分布和标本采集都呈现出很强的地域 性。结合气候因子进行模型模拟的结果表明, 温度 限定了竹类植物两大分支各自的分布北界, 水分条
件对温带木本竹类的限制作用更强, 而温度对旧世 界热带木本竹类的限制性更强; 对竹类适生区的模 拟结果发现, 竹类两大分支在国内的适生区出现了 明显的分化, 但仍有部分重叠。值得注意的是, 两 大分支在四川盆地和云南南部的适生度都很高, 但 在低海拔的盆地或河谷区域, 旧世界热带木本竹类 仍然占据主要生态位。四川盆地在纬度范围内处于 温带木本竹类的适生区内, 但模拟结果却发现该地 是旧世界热带木本竹类和温带木本竹类的适生重 叠区, 其盆地的中心位置是旧世界热带木本竹类的 适生区, 该结果最早被吴征镒等(1980)在《中国植 被》中对中国竹林分区的划分结果中体现, 该研究 中单独将四川盆地划为混生竹区。其次云南大部分 区域也属于两大分支的适生重叠区, 这与我们野外 考察的结论相吻合, 同时也揭示了云南省竹类资源 丰富的原因。依据标本数据, 我们得以从更深层次 解释宏观层面所观察到的地理分布状况, 或可为其 他植物类群的研究提供一种新的模式。

综上所述, 植物标本记录了特定类群在时间和 空间地理上的分布格局, 相关的信息一方面可以促 进物种灭绝风险评估、可持续利用和综合保护, 另 一方面也可助力大尺度生物多样性分布格局及全 球变化对多样性的影响研究。

致谢: 感谢莫智琼女士在数据分析中提供的帮助; 感谢审稿专家提出的宝贵意见!

\section{ORCID}

许祖昌 (D) https://orcid.org/0000-0001-7431-1061 李德铢 (iD https://orcid.org/0000-0002-4990-724X

\section{参考文献}

Boyle B, Hopkins N, Lu ZY, Raygoza Garay JA, Mozzherin D, Rees T, Matasci N, Narro ML, Piel WH, McKay SJ, Lowry S, Freeland C, Peet RK, Enquist BJ (2013) The taxonomic name resolution service: An online tool for automated standardization of plant names. BMC Bioinformatics, 14, 16.

Bridson D, Forman L (translated by Yao YJ, Xia NH, Li DZ, Li Y) (1998) The Herbarium Handbook, 3rd edn), pp. 184-242. Royal Botanic Gardens Kew. (in Chinese) [姚一 建, 夏念和, 李德铢, 李玉 (译) (1998) 标本馆手册(第3 版), pp. 184-242. 英国邱园皇家植物园.]

Chao A (1984) Nonparametric estimation of the number of classes in a population. Scandinavian Journal of Statistics, 11, 265-270. 
Chu C, Smith W, Solow A (2014) A hidden species-area curve. Environmental and Ecological Statistics, 21, 113-124.

Clark LG, Oliveira RP (2018) Diversity and evolution of the new world bamboos (Poaceae: Bambusoideae: Bambuseae, Olyreae). Keynote lecture in the 11th World Bamboo Congress, 14-18th August 2018. Xalapa, Mexico.

Cui XY, Wang WJ, Yang XQ, Li S, Qin SY, Rong J (2016) Potential distribution of wild Camellia oleifera based on ecological niche modeling. Biodiversity Science, 24, 1117-1128. (in Chinese with English abstract) [崔相艳, 王 文娟, 杨小强, 李述, 秦声远, 戎俊 (2016) 基于生态位 模型预测野生油茶的潜在分布. 生物多样性, 24, 1117-1128.]

GPWG (Grass Phylogeny Working Group) (2001) Phylogeny and subfamilial classification of the grasses (Poaceae). Annals of the Missouri Botanical Garden, 88, 373-457.

GPWG II (Grass Phylogeny Working Group II) (2012) New grass phylogeny resolves deep evolutionary relationships and discovers $\mathrm{C}_{4}$ origins. New Phytologist, 193, 304-312.

Guo ZH, Ma PF, Yang GQ, Hu JY, Liu YL, Xia EH, Zhong MC, Zhao L, Sun GL, Xu YX, Zhao YJ, Zhang YC, Zhang YX, Zhang XM, Zhou MY, Guo Y, Guo C, Liu JX, Ye XY, Chen YM, Yang Y, Han B, Lin CS, Lu Y, Li DZ (2019) Genome sequences provide insights into the reticulate origin and unique traits of woody bamboos. Molecular Plant, 12, 1353-1365.

He X, Burgess KS, Gao LM, Li DZ (2019) Distributional responses to climate change for alpine species of Cyananthus and Primula endemic to the Himalaya-Hengduan Mountains. Plant Diversity, 41, 26-32.

Hijmans RJ, Cameron SE, Parra JL, Jones PG, Jarvis A (2005) Very high resolution interpolated climate surfaces for global land areas. International Journal of Climatology, 25, 1965-1978.

Janzen DH (1976) Why bamboos wait so long to flower? Annual Review of Ecology and Systematics, 7, 347-391.

Kelchner SA, Bamboo Phylogeny Group (BPG) (2013) Higher level phylogenetic relationships within the bamboos (Poaceae: Bambusoideae) based on five plastid markers. Molecular Phylogenetics and Evolution, 67, 404-413.

Keng PC (1983) A revision of the genera of bamboos from the world (III). Journal of Bamboo Research, 2(1), 11-27. (in Chinese with English abstract) [耿伯介 (1983) 世界竹亚 科各属的考订(之三). 竹子研究汇刊, 2(1), 11-27.]

Keng PC (1984) A revision of the genera of bamboos from the world (V). Journal of Bamboo Research, 3(1), 22-42. (in Chinese with English abstract) [耿伯介 (1983) 世界竹亚 科各属的考订(之五). 竹子研究汇刊, 3(1), 22-42.]

Li DZ, Wang ZP, Zhu ZD, Xia NH, Jia LZ, Guo ZH, Yang GY, Stapleton CMA (2006) Bambuseae (Poaceae). In: Flora of China, Vol. 22 (eds Wu ZY, Raven PH, Hong DY), pp. 7-180. Science Press, Beijing \& Missouri Botanical Garden Press, St. Louis.
Liu CR, Berry PM, Dawson TP, Pearson RG (2005) Selecting thresholds of occurrence in the prediction of species distributions. Ecography, 28, 385-393.

Menard SW (2001) Applied Logistic Regression Analysis. Series: Quantitative Applications in the Social Sciences (Book 106), pp. 111. SAGE Publications, 2nd edition,

McClure FA (1966) The bamboos: A fresh perspective. BioScience, 18, 129-130.

Nakai T (1931) Hokkaido Teikoku Daigaku Nogakubu Kiyo. Journal of the Faculty of Agriculture, 26, 180.

Phillips SJ, Anderson RP, Schapire RE (2006) Maximum entropy modeling of species geographic distributions. Ecological Modelling, 190, 231-259.

Saarela JM, Burke SV, Wysocki WP, Barrett MD, Clark LG, Craine JM, Peterson PM, Soreng RJ, Vorontsova MS, Duvall MR (2018) A 250 plastome phylogeny of the grass family (Poaceae): Topological support under different data partitions. PeerJ, 6, e4299.

Soderstrom TR, Young SM (1983) A guide to collecting bamboos. Annals of the Missouri Botanical Garden, 70, 128-136.

Soreng RJ, Peterson PM, Romaschenko K, Davidse G, Teisher JK, Clark LG, Barberá P, Gillespie LJ, Zuloaga FO (2017) A worldwide phylogenetic classification of the Poaceae (Gramineae) II: An update and a comparison of two 2015 classifications. Journal of Systematics and Evolution, 55, 259-290.

Stapleton CMA (2004) Sarocalamus, a new Sino-Himalayan bamboo genus (Poaceae-Bambusoideae). Novon, 14, 346-347.

Tittensor DP, Mora C, Jetz W, Lotze HK, Ricard D, Berghe EV, Worm B (2010) Global patterns and predictors of marine biodiversity across taxa. Nature, 466, 1098-1101.

Turland N, Wiersema J, Barrie F, Greuter W, Hawksworth D, Herendeen P, Knapp S, Kusber WH, Li DZ, Marhold K, May T, McNeill J, Monro A, Prado J, Price M, Smith G (2018) International Code of Nomenclature for Algae, Fungi, and Plants (Shenzhen Code). https://www.iapt-taxon. org/nomen/main.php. (accessed on 2019-01-27)

Vorontsova MS, Clark LG, Dransfield J, Govaerts R, Baker WJ (2016) World Checklist of Bamboos and Rattans, p. 102. Science Press, Beijing.

Wang KL, Chen JX, Fan X (2018) Analysis of geographical deviation of record collection of Rosaceae plant specimens in national specimen resource sharing platform. e-Science Technology \& Application, 9(5), 5463. (in Chinese with English abstract) [王凯莉, 陈佳欣, 范雪 (2018) 国家标 本资源共享平台蓄薇科植物标本记录采集地理偏差分析. 科研信息化技术与应用, 9(5), 54-63.]

Wang RZ, Li SJ, Zhang DX (2012) Statistical analyses of vascular plant specimen data from the herbarium of South China Botanical Garden, Chinese Academy of Sciences (IBSC). Journal of Tropical and Subtropical Botany, 20, 
634-641. (in Chinese with English abstract) [王仁赞, 李世 晋, 张奠湘 (2012) 中国科学院华南植物园标本馆维管 植物标本数据统计分析. 热带亚热带植物学报, 20, 634-641.]

Wang YS, Xie BY, Wan FH, Xiao QM, Dai LY (2007) Application of ROC curve analysis in evaluating the performance of alien species' potential distribution models. Biodiversity Science, 15, 365-372. (in Chinese with English abstract) [王运生, 谢丙炎, 万方浩, 肖启明, 戴良英 (2007) ROC曲线分析在评价入侵物种分布模型中的应用. 生物多样性, 15, 365-372.]

Wong KM (1993) Four new genera of bamboos (Gramineae: Bambusoideae) from Malesia. Kew Bulletin, 48, 517-532.

Wu ZY (1980) Vegetation of China, pp. $411-416$. Science Press, Beijing. (in Chinese) [吴征镒 (1980) 中国植被, 411-416页. 科学出版社, 北京.]

Yang WJ (2013) Geographical Sampling Bias in the Collections of Chinese Plants and Its Impacts on the Analysis of Biodiversity Patterns. PhD dissertation, Insititute of Botany, Chinese Academy of Sciences, Beijing. (in Chinese with English abstract) [阳文静 (2013) 中国植 物采集的地理偏差及其对生物多样性格局分析的影响, 博士学位论文, 中国科学院植物研究所, 北京.]
Yang Y (2012) Holdings of type specimens of plants in herbaria of China. Biodiversity Science, 20, 512-516. (in Chinese with English abstract) [杨永 (2012) 我国植物模式标本的 馆藏量. 生物多样性, 20, 512-516.]

Zeng CX, Hollingsworth PM, Yang J, He ZS, Zhang ZR, Li DZ, Yang JB (2018) Genome skimming herbarium specimens for DNA barcoding and phylogenomics. Plant Methods, 14, 1-14.

Zhang YX, Ma PF, Li DZ (2018) A new genus of temperate woody bamboos (Poaceae, Bambusoideae, Arundinarieae) from a limestone montane area of China. PhytoKeys, 109, 67-76.

Zhang YX, Ren M, Xiao C (2018) The analysis of geographical bias of the collection of Chinese Rhododendraceae plants based on the data of National Specimen Information Infratructure. E-Science Technology \& Application, 9(5), 72-83. (in Chinese with English abstract) [张玉雪, 任敏, 肖翠 (2018) 基于国家标本资源共享平台数据的中国杜 鹃花科植物标本采集地理偏差分析. 科研信息化技术与 应用, 9(5), 72-83.]

(责任编委: 王志恒 责任编辑: 黄祥忠)

\section{附录 Supplementary Material}

附录1 比值与标本采集量的相关性检测。A：各省区比值与标本采集量的相关性; B: 竹类各属比值与标本采集量的相关性。 Appendix 1 Correlation analysis of ratio and specimen collections. A, Correlation analysis of ratio and specimen collections at the province level; B, Correlation analysis of ratio and specimen collections at the generic level.

http://www.biodiversity-science.net/fileup/PDF/2020373-1.pdf

附录2 标本馆索引接受的主要标本馆名称及国际标准代码

Appendix 2 Major herbaria and their standard code, adopted from Index Herbariorum http://www.biodiversity-science.net/fileup/PDF/2020373-2.pdf 
许祖昌, 罗亚皇, 秦声远, 朱光福, 李德铢 (2021) 中国竹类植物馆藏标本现状与地理分布. 生物多样性, 29, 897-909. http://www.biodiversity-science.net/CN/10.17520/biods.2020373
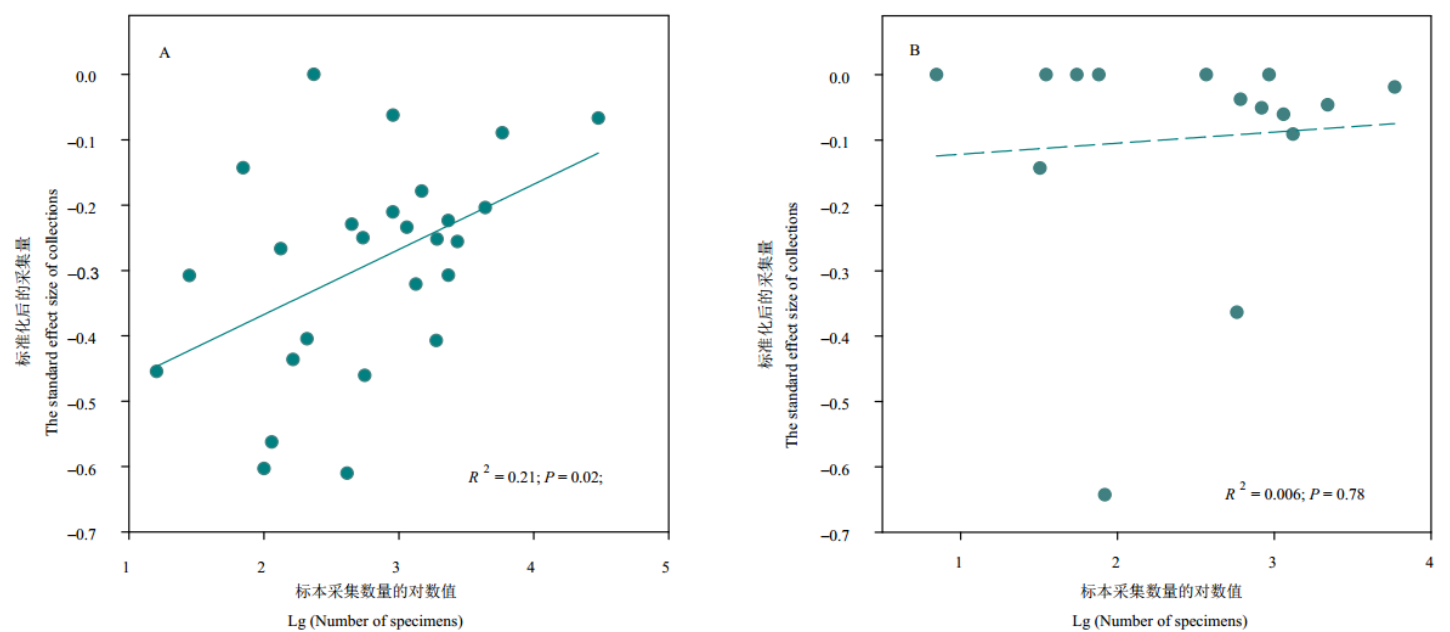

附录1 比值与标本采集量的相关性检测。 $\mathrm{A}$ : 各省区比值与标本采集量的相关性; B: 竹类各属比值与标本 采集量的相关性。

Appendix 1 Correlation analysis of ratio and specimen collections. A, Correlation analysis of ratio and specimen collections at the province level; B, Correlation analysis of ratio and specimen collections at the generic level. 
许祖昌, 罗亚皇, 秦声远, 朱光福, 李德铢 (2021) 中国竹类植物馆藏标本现状与地理分布. 生物多样性, 29, 897-909. http://www.biodiversity-science.net/CN/10.17520/biods.2020373

附录2 标本馆索引接受的主要标本馆名称及国际标准代码

Appendix 2 Major herbaria and their standard code, adopted from Index Herbariorum 机构

Institution

华中师范大学生命科学学院植物标本馆

标本馆代码

Herbarium, School of Life Science, Central China Normal University

河南农业大学植物标本室

Herbarium Code

Herbarium, Henan Agricultural University

杭州植物园标本室

Herbarium, Hangzhou Botanical Garden

中国科学院西双版纳热带植物园植物标本馆

$\mathrm{CCNU}$

Herbarium, Xishuangbanna Tropical Botanical Garden, Chinese Academy of Sciences

湖南师范大学生命科学学院植物标本室

Herbarium, College of Life Science, Hunan Normal University

广西壮族自治区中国科学院广西植物研究所植物标本馆

HEAC

Herbarium, Guangxi Institute of Botany, Guangxi \& Chinese Academy of Sciences

中国科学院华南植物园植物标本馆

HHBG

Herbarium, South China Botanical Garden, Chinese Academy of Sciences

重庆市药物种植研究所标本馆

Herbarium, Chongqing Institute of Medicinal Plant Cultivation

中国科学院昆明植物研究所标本馆

HITBC

Herbarium, Kunming Institute of Botany, Chinese Academy of Sciences

南京大学生命科学学院植物标本室

Herbarium, School of Life Science, Nanjing University

江苏省中国科学院植物研究所标本馆

Herbarium, Institute of Botany, Jiangsu Province \& Chinese Academy of Sciences

南京林业大学树木标本室

Dendrological Herbarium, Nanjing Forestry University

中国科学院植物研究所植物标本馆

HNNU

Herbarium, Institute of Botany, Chinese Academy of Sciences

西南林业大学林学院植物标本室

IBK

IBSC

IMC

KUN

$\mathrm{N}$

NAS

NF

PE

Herbarium, College of Forestry, Southwest Forestry University

中山大学生命科学学院生物博物馆植物标本室

SWFC

Herbarium, Biological Museum, School of Life Sciences, Sun Yat-Sen University

四川大学生命科学学院自然博物馆植物标本室

SYS

Herbarium, Museum of Natural History, College of Life Sciences, Sichuan University

SZ 